\title{
Atherosclerosis risk assessment in patients with chronic obstructive pulmonary disease: a case-control study
}

This article was published in the following Dove Press journal:

Therapeutics and Clinical Risk Management

\author{
Himanshu Sharma' \\ Prem Kapur ${ }^{2}$ \\ Rajinder $\mathrm{K}$ Jalali ${ }^{3}$ \\ Kiran Dubey'
}

'Department of Pharmacology, School of Pharmaceutical Education and Research, Jamia Hamdard, New Delhi I I0062, India; ${ }^{2}$ Department of Medicine, Hamdard Institute of Medical Sciences and Research (HIMSR) and HAH-Centenary Hospital, Jamia Hamdard, New Delhi, India; ${ }^{3}$ Sushant Lok Phase-I, Gurgaon, Haryana 12200I, India
Correspondence: Kiran Dubey Department of Pharmacology, School of Pharmaceutical Education and Research, Jamia Hamdard, New Delhi I 10062, India Tel +9l 981 0590843

Email kirandubey@gmail.com
Purpose: Chronic Obstructive Pulmonary Disease (COPD) is considered as a risk factor for atherosclerosis and a leading cause of mortality due to cardiovascular disease (CVD). The study assessed the association of COPD with atherosclerotic risk factors and compared the predictor role of various cardiovascular (CV) risk score calculators in Indian subjects with COPD.

Patients and methods: Forty subjects with stable COPD and forty age, gender and body mass index (BMI)-matched healthy controls were included in the case-control study conducted in a tertiary care hospital. Atherogenic indices were calculated by using the values of lipid parameters. CV risk calculators were utilized to assess the 10-year CV risk for the COPD group.

Results: The study subjects had a mean age of $60.83 \pm 12.40$ years in COPD group and 57.73 \pm 9.49 years in control group $(p=0.213$ ). Gender distribution was similar in both the groups. The mean High sensitivity C-reactive protein ( $h s$-CRP) levels were $3.70 \pm 2.37 \mathrm{mg} / \mathrm{L}$ in COPD group and $2.39 \pm 2.23 \mathrm{mg} / \mathrm{L}$ in control group. The $h s$-CRP levels were significantly higher in COPD than in control subjects $(p=0.012)$. Using bivariate correlations, we found significant positive correlations between $h s$-CRP and atherogenesis indices-atherogenic index of plasma, cardiogenic risk ratio, atherogenic coefficient in COPD patients $[(\mathrm{r}=0.4265$, $p<0.006) ;(\mathrm{r}=0.7034, p<0.001)$ and $(\mathrm{r}=0.7034, p<0.001)$, respectively]. Framingham risk score-cardiovascular disease (FRS-CVD) has identified maximum number of COPD subjects (45\%) to be in high CVD risk category.

Conclusion: The study concluded that $h s$-CRP levels in COPD subjects were significantly higher than in control subjects. FRS-CVD was most useful for identifying high CV risk subjects in COPD subjects.

Keywords: cardiovascular, CVD risk calculator, $h s-\mathrm{CRP}$, atherogenesis indices

\section{Introduction}

Chronic Obstructive Pulmonary Disease (COPD) is a complex, heterogeneous, preventable and treatable chronic respiratory disease, characterized by progressive, poorly reversible airflow limitation often with systemic manifestations. It is one of the leading causes of death and morbidity worldwide accounting for 3 million deaths. ${ }^{1,2}$ COPD often coexists with cardiovascular (CV) morbidity. The relationship between cardiovascular diseases (CVDs) and COPD has been reported in many studies. $^{3-5}$ The common systemic inflammatory pathway in the pathogenesis of both these diseases is one of the main reasons for the co-morbidity. ${ }^{4,5}$ 
Atherosclerosis is the main reason causing CVDs and the leading cause of global morbidity and mortality. Many studies have tried evaluating the early prediction of the presence of $\mathrm{CV}$ risk factors on atherosclerosis. ${ }^{6,7}$ For these prediction algorithms, several lipoprotein ratios or atherogenic indices (atherogenic index of plasma, cardiogenic risk ratio and atherogenic coefficient) have been defined and investigated in several conditions. ${ }^{6-9}$ The association between atherogenic indices in subjects with COPD has not been studied comprehensively.

Models to predict future CV risk are important in the management of CVDs. Many risk estimation systems are in existence. ${ }^{10-12}$ The best known and probably the most widely used globally is the Framingham risk score-cardiovascular disease (FRS-CVD). Modified versions of the 10-year FRS-CVD calculator equation are also used for identifying high-risk populations and include Joint British Society-3 (JBS3), QRISK2, Reynolds risk score (RRS) calculators. Various factors like local applicability and modifiability of the risk prediction model play a role in their assessment of the $\mathrm{CV}$ risk. C-reactive protein (CRP) is a potential biomarker of systemic inflammation and is often increased in COPD patients. ${ }^{13-16}$

The present study aimed to evaluate $h s-C R P$ levels, atherogenic indices, atherosclerosis risk factors and assess the 10-year CV risk in Indian subjects with COPD. The article is adapted in line with the STROBE guidelines for reporting observational studies. ${ }^{17}$

\section{Materials and methods}

The statement for Strengthening the Reporting of Observational Studies in Epidemiology (STROBE) was followed in reporting observations for this study. ${ }^{17}$

\section{Study design}

This case-control study was conducted in a clinical setting at the Hamdard Institute of Medical Sciences \& Research (HIMSR), Jamia Hamdard, New Delhi, India, from June 2015 to December 2017, after getting the approval from the Jamia Hamdard Institutional Ethics Committee (JHIEC), Delhi, India.

Study-related activities were started after obtaining a written informed consent from all the study participants. The principles enumerated in the Declaration of Helsinki and the WHO standards for observational studies were followed throughout the conduct of this study. ${ }^{18,19}$
Systematic representation of screening, enrollment, data collection and analysis of study participants is presented in Figure 1.

\section{Sample size}

In a previous study conducted in similar Indian population, difference in Low-Density Lipoprotein Cholesterol (LDL-C) between Healthy Control and Mild Smoker (Delta) was noted as 12 units. Standard deviation (SD) in the control group was observed as 17.6 units. ${ }^{20}$ Considering these inputs and $85 \%$ power, a sample size of 40 subjects in each group is sufficient to meet the study objects at two-sided 5\% alpha level.

\section{Inclusion and exclusion criteria}

Subjects of both gender, age 40 years and above were included in the study. Stable cases of COPD without exacerbation constituted Group 1 whereas age, gender and Body Mass Index (BMI)-matched healthy subjects served as control (Group 2).

Subjects with primary diagnosis/history of another respiratory disease such as asthma, restrictive disorders like tuberculosis sequelae or interstitial fibrosis, obstructive sleep apnea-hypopnea syndrome, lung cancer, recent or ongoing infection or fever, chronic inflammatory disorders like rheumatoid arthritis, systemic lupus erythematosus and primary diagnosis of unstable angina, congestive heart failure (New York Heart Association functional class III or IV), active coronary artery disease or any other chronic disease, such as uncontrolled Diabetes Mellitus, kidney failure, liver disease were excluded from the study. Also, pregnant and lactating women and patients with altered mental status were excluded from the study.

\section{Enrollment and data collection}

The study included 40 patients of COPD, comprising the case group. First, COPD cases were recruited in the study. Their data with respect to age, gender and Body Mass Index (BMI) were used to select matched healthy subjects visiting the hospital. The control group consisted of 40 healthy volunteers visiting the hospital with patients as their attendants or caretakers during the period. All the study subjects belonged to diverse socio-economic background.

Rigorous evaluation of present and past health conditions of all study participants was carried out using i) vital sign; ii) their medical records in the hospital database; iii) medication history (subjects were asked to bring their 


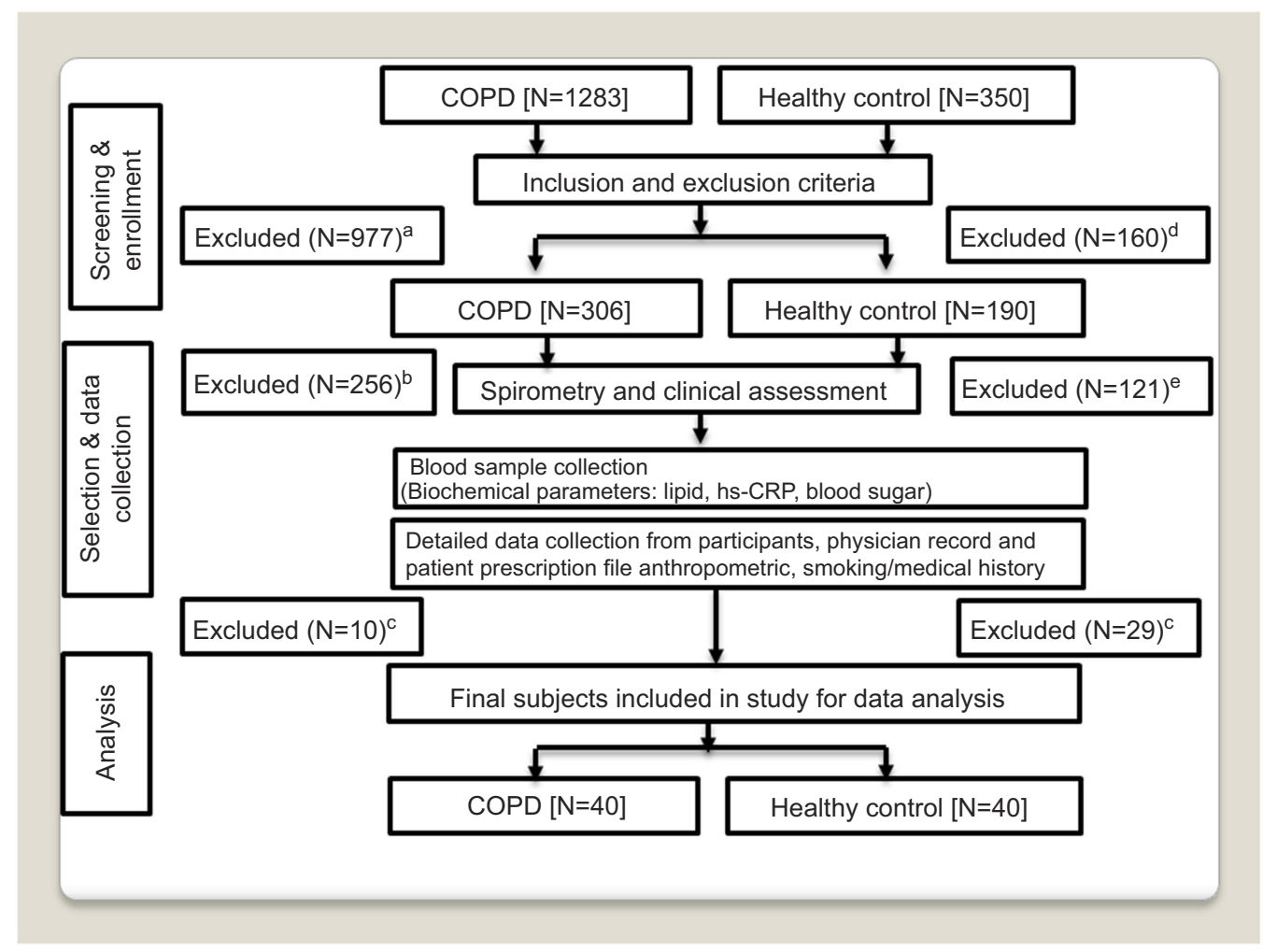

Figure I Study flow diagram.

Notes: ${ }^{\mathrm{a}} \mathrm{COPD}$ subjects with other concomitant diseases such as hypertension, diabetes, tuberculosis, coronary artery disease (stroke and TIA), cardiovascular disease, liver disease, kidney failure, other respiratory conditions, infections and inflammatory conditions. ${ }^{b} \mathrm{COPD}$ subjects with post-bronchodilator FEVI reversibility $>12 \%$. ${ }^{\mathrm{C}}$ Missing data. ${ }^{\mathrm{d}} \mathrm{C}$ (ontrol subject with any concomitant diseases such as hypertension, diabetes, tuberculosis, coronary artery disease (stroke and TIA), cardiovascular disease, liver disease, kidney failure, other respiratory conditions, infections and inflammatory conditions. ${ }^{\mathrm{e}} \mathrm{Abnormal}$ spirometry values vs predicted values for healthy subjects with the same anthropometric details. Abbreviation: COPD, chronic obstructive pulmonary disease.

daily medicines including those prescribed in the past 1 year and/or all prescription of doctors); and iv) detailed interview by a health care provider to exclude the subjects with CV events before enrolling any subjects in the study.

Once enrolled in the study, spirometry and clinical assessment were performed. After spirometry assessment, the confirmed case/control subjects were considered for biochemical analyses. The demographic details were collected from all the selected subjects after biochemical analyses. Spirometry was conducted for all the subjects as per the method defined in GOLD guideline. In order to minimize variability, Spirometry was repeated after the administration of $400 \mathrm{mcg}$ of salbutamol (a short-acting inhaled bronchodilator) in the COPD subjects.

Blood samples were collected from overnight fasting enrolled subjects once in the study. Biochemical analyses included fasting plasma glucose, high sensitive C-reactive protein (hs-CRP), total cholesterol (TC), low-density lipoprotein cholesterol (LDL-C), high-density lipoprotein cholesterol (HDL-C) and triglycerides (TG) levels.

\section{Pulmonary function test (PFT) and interpretation of data}

Spirometry was performed in sitting position after recording age, gender, weight, height readings and as per criteria for standardization of spirometry defined by American Thoracic Society (ATS)/European Respiratory Society (ERS) task force and in GOLD 2016. ${ }^{1,21,22}$ Pre- and post-bronchodilator test were performed on clinically confirmed cases of COPD in line with ATS/ERS task force and in GOLD 2016. ${ }^{1,21,22}$ Salbutamol (400 mcg) was used as short-acting beta-agonist.

As per GOLD 2016, the presence of a post-bronchodilator FEV1/FVC $<0.70$ confirms the presence of persistent airflow limitation and thus of COPD. Further, to minimize the variability, COPD cases showing $>12 \%$ change in FEV1 value after post-bronchodilator were excluded. ${ }^{23} \mathrm{COPD}$ subjects were categorized into groups $\mathrm{A}-\mathrm{D}$ according to combined COPD risk assessment categories defined by GOLD. ${ }^{1}$

Interpretation of PFT is based on comparison of data measured in an individual subject with reference 
(predicted) values based on healthy subjects with the same anthropometric (eg, sex, age and height). Age, gender, BMI-matched subjects without any disease and $\geq 100 \%$ predicted FEV1 value were included in control group.

\section{Atherogenic indices}

Atherogenic indices were calculated by using the value of lipid profile parameters according to the following formulae: Atherogenic Index for Plasma (AIP) $=\log$ (triglyceride/ high-density lipoprotein cholesterol), with the concentrations in $\mathrm{mmol} / \mathrm{L}$; Cardiogenic Risk Ratio $(\mathrm{CRR})=$ total cholesterol/high-density lipoprotein cholesterol; and Atherogenic Coefficient $(\mathrm{AC})=$ (total cholesterol-highdensity lipoprotein cholesterol)/high-density lipoprotein cholesterol. $^{7,8,24}$

\section{Cardiovascular risk estimation}

$\mathrm{CV}$ risk prediction models of Joint British Society calculator-3 (JBS3), QRISK2, Reynolds risk score (RRS) and FRS-CVD were utilized to assess the 10-year CV risk for the COPD group. Age, gender, systolic blood pressure, total \& HDL cholesterol, smoking status and treatment for hypertension were considered in FRS-CVD calculation. In QRISK2, the presence of chronic kidney disease, atrial fibrillation, rheumatoid arthritis, family history of CVD, ethnicity along with body mass index were also considered along with the classical risk factors. JBS3 used the same risk factors for risk score calculation as
QRISK2. RRS included parental history of premature coronary heart disease and $h s$-CRP. ${ }^{10,11,25,26}$

\section{Statistical analysis}

Statistical analysis for the study was performed with SPSS version 20. Categorical variables were specified as $n(\%)$. All continuous variables were specified as mean $\pm \mathrm{SD}$ when normally distributed or median [interquartile range (IQR)] when not normally distributed. Proportions in the different groups were compared by using the chi-square test. Comparisons between the groups were done using Student's unpaired $t$-test or Mann-Whitney U test wherever appropriate. The Spearman's correlation test was used to analyze the correlation coefficients and their significance. A linear regression model was used to determine independent predictors of all atherogenic indices. $p$-values $<0.05$ were set to show a statistically significant result.

\section{Results}

A total of 1283 physician-diagnosed COPD subjects and age, gender-matched 350 healthy subjects were screened between the study periods. A large number $(\mathrm{N}=977)$ of follow-up cases of COPD subjects who were admitted in the hospital were excluded due to the presence of comorbid conditions. Subjects meeting the initial screening criteria were further evaluated as shown in Figure 1. The distribution of comorbidities is shown in Figure 2. Three hundred fifty-three subjects $(27.5 \%)$ had at least two comorbidities and five hundred sixty-six subjects (44\%)

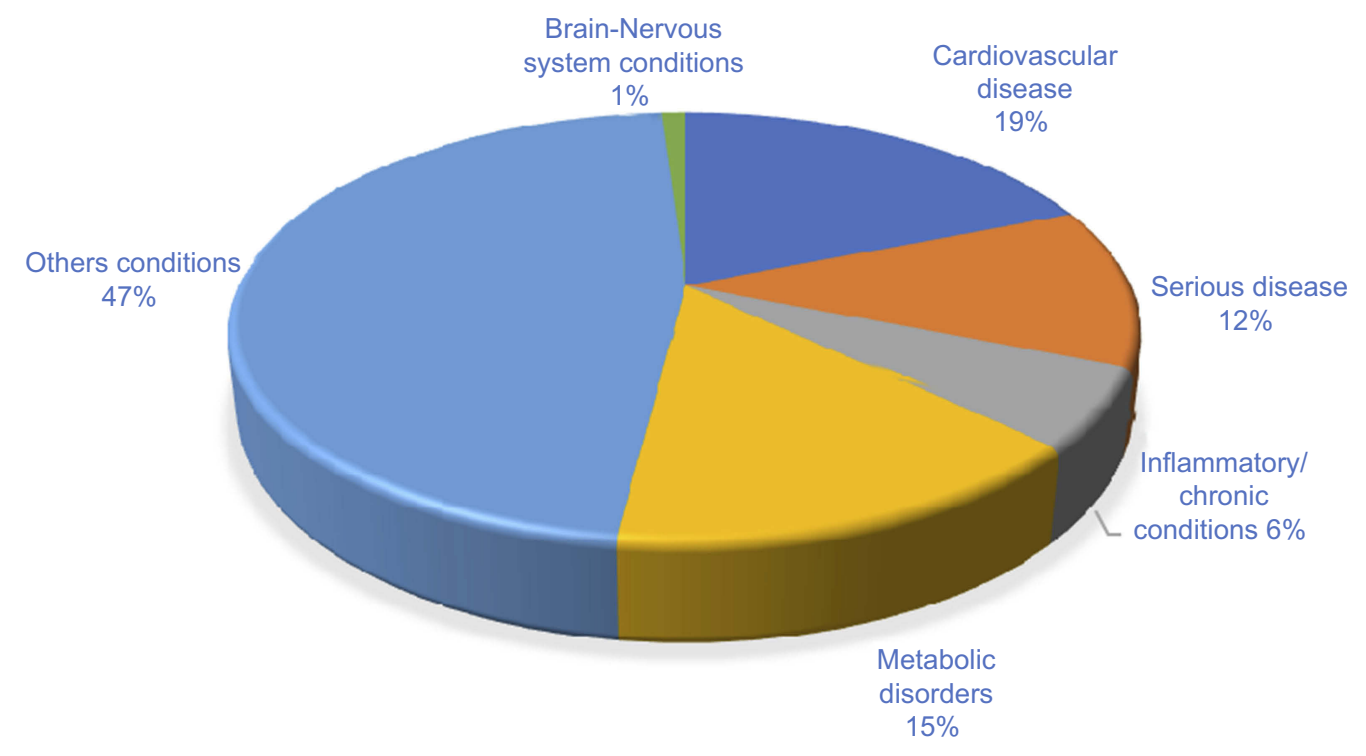

Figure 2 Comorbidities in COPD patients - exclusion during initial screening.

Abbreviation: COPD, chronic obstructive pulmonary disease. 
had at least one comorbidity. Key CV comorbidities in COPD patients were hypertension, coronary artery disease and stroke. Key metabolic disorders in COPD patients were diabetes, thyroid disease and nutrition deficiencies such as anemia and Vitamin D deficiency. Cases of liver disease, gallbladder disease and kidney/prostate disease were the main inflammatory/chronic conditions in COPD patients. Key brain-nervous system disorders were Parkinson's disease, neuropathy, schizophrenia and cases of depression and anxiety. Main serious disease conditions were cases of tuberculosis, septicemia and cancer. Other non-chronic and less-serious conditions such as fever, pain and common infections were grouped together in Figure 2.

The demographic characteristics, pulmonary function parameters of subjects in both groups (COPD, $n=40$; healthy controls, $\mathrm{n}=40$ ) and COPD stages of the cases are outlined in Table 1. Age was statistically similar in both groups with mean ages of $60.83 \pm 12.40$ years and $57.73 \pm 9.49$ years, respectively, for the COPD and the control group. Gender distribution was similar in both

Table I Baseline characteristics of subjects in COPD and control groups

\begin{tabular}{|c|c|c|c|c|}
\hline \multicolumn{2}{|l|}{ Parameters } & Control & COPD & $p$-value \\
\hline \multicolumn{2}{|l|}{ Age (years), mean $\pm S D$} & $57.73(9.49)$ & $60.83(12.40)$ & $0.213^{\mathrm{a}}$ \\
\hline \multicolumn{5}{|l|}{ Gender } \\
\hline \multirow{2}{*}{\multicolumn{2}{|c|}{$\begin{array}{l}\text { Male }(n=60 ; 75 \%) \\
\text { Female }(n=20 ; 25 \%)\end{array}$}} & $30(75 \%)$ & $30(75 \%)$ & \\
\hline & & $10(25 \%)$ & $10(25 \%)$ & \\
\hline \multicolumn{2}{|l|}{ BMI $\left(\mathrm{kg} / \mathrm{m}^{2}\right)$, mean \pm SD } & $25.72 \pm 5.59$ & $24.40 \pm 5.45$ & $0.288^{\mathrm{a}}$ \\
\hline \multicolumn{5}{|l|}{ Smoking status, n (\%) } \\
\hline \multirow{3}{*}{\multicolumn{2}{|c|}{$\begin{array}{l}\text { Current smoker }(n=14 ; 17.5 \%) \\
\text { Ex-smoker }(n=22 ; 27.5 \%) \\
\text { Non-smoker }(n=44 ; 55 \%)\end{array}$}} & $6(15)$ & $8(20) * * *$ & $<0.001^{\mathrm{b}}$ \\
\hline & & $2(5)$ & $20(50) * * *$ & \\
\hline & & $32(80)$ & $12(30) * * *$ & \\
\hline \multicolumn{2}{|l|}{ Smoking (years), mean \pm SD pack } & $19.43 \pm 8.14$ & $25.63 \pm 15.88^{*}$ & 0.031 \\
\hline \multicolumn{5}{|l|}{ Pulmonary function test } \\
\hline \multirow[t]{4}{*}{$\mathrm{FVC}(\mathrm{L})$} & IQR & 0.90 & 0.73 & $<0.001^{\mathrm{c}}$ \\
\hline & Quartile I & 2.66 & 1.44 & \\
\hline & Median & 3.00 & 1.88 & \\
\hline & Quartile 3 & 3.51 & 2.17 & \\
\hline \multirow[t]{4}{*}{$\mathrm{FEV}_{1} \%$ predicted } & IQR & 17.00 & 18.48 & $<0.001^{\mathrm{c}}$ \\
\hline & Quartile I & 85.75 & 33.53 & \\
\hline & Median & 94.50 & 41.72 & \\
\hline & Quartile 3 & 104.5 & 52.01 & \\
\hline \multirow[t]{4}{*}{$\mathrm{FEV}_{1} / \mathrm{FVC} \%$ predicted } & IQR & 9.15 & 16.62 & $<0.001^{\mathrm{c}}$ \\
\hline & Quartile I & 79.13 & 48.89 & \\
\hline & Median & 84.65 & 56.52 & \\
\hline & Quartile 3 & 88.78 & 65.51 & \\
\hline \multicolumn{5}{|c|}{ Characteristic of COPD patients } \\
\hline \multirow[t]{4}{*}{ COPD stages, n (\%) } & & Stage A & $0(0)$ & \\
\hline & & Stage B & $12(30)$ & \\
\hline & & Stage C & $22(55)$ & \\
\hline & & Stage D & $6(15)$ & \\
\hline \multirow[t]{2}{*}{ Risk category, n (\%) } & & Lower risk & $12(30)$ & \\
\hline & & Higher risk & $28(70)$ & \\
\hline
\end{tabular}

Notes: ${ }^{a}$ Student $t$-test; ${ }^{b}$ Chi-square test; ${ }^{c}$ Mann-Whitney $U$ test; ${ }^{*} p<0.05 ; * * p<0.01 ; * * * p<0.00$ I.

Abbreviations: BMI, body mass index; IQR, interquartile range; FVC, forced vital capacity; FEVI, forced expiratory volume in one second; COPD, chronic obstructive pulmonary disease. 
Table 2 Lipid profile and atherogenic indices of COPD and control subjects

\begin{tabular}{|l|l|l|l|}
\hline Parameters & Control & COPD & -value \\
\hline Total Cholesterol (mg/dL), mean \pm SD & $177.10 \pm 35.41$ & $173.88 \pm 19.81$ & 0.617 \\
HDL Cholesterol (mg/dL), mean \pm SD & $47.68 \pm 9.99$ & $39.03 \pm 6.83^{* * *}$ & $<0.001$ \\
LDL Cholesterol (mg/dL), mean \pm SD & $99.35 \pm 22.43$ & $111.40 \pm 22.76^{*}$ & 0.019 \\
AIP, mean \pm SD & $0.47 \pm 0.26$ & $0.49 \pm 0.19$ & 0.696 \\
CRR, mean \pm SD & $3.86 \pm 1.07$ & $4.64 \pm 1.22^{* *}$ & 0.003 \\
AC, mean \pm SD & $2.86 \pm 1.07$ & $3.64 \pm 1.22^{* *}$ & 0.003 \\
\hline
\end{tabular}

Notes: Student's t-test; $*_{p}<0.05 ;{ }^{* *} p<0.01 ; * * * p<0.001$.

Abbreviations: HDL, high-density lipoprotein; LDL, low-density lipoprotein; AIP, atherogenic index of plasma; CRR, cardiogenic risk ratio; AC, atherogenic coefficient; COPD, chronic obstructive pulmonary disease.

the groups (30 males and 10 females). Smoking status was significantly more in the COPD group $(p<0.001)$, as was cigarette consumption in cases than in control subjects $(25.63 \pm 15.88$ and $19.43 \pm 8.14$, respectively, $p=0.031)$.

Lipid profile and atherogenic indices of the two groups are outlined in Table 2. Distribution of hs-CRP and triglycerides of COPD and control subjects is presented in Table 3. hs-CRP levels were significantly higher in COPD than in control subjects $(p=0.012)$. Serum highdensity lipoprotein cholesterol level was significantly lower in subjects with COPD $(p<0.001)$. Serum low-density lipoprotein cholesterol level was significantly higher in subjects with COPD than in control subjects $(p=0.019)$. Atherogenic indices- cardiogenic risk ratio (CRR) and atherogenic coefficient (AC) were significantly higher in subjects with COPD than in control subjects $(p=0.003)$ for both the parameters.

Bivariate correlations with C-reactive protein in COPD and control subjects are presented in Table 4. Significant positive correlations between atherogenesis indices-atherogenic indices in plasma (AIP), cardiogenic risk ratio (CRR), atherogenic coefficient (AC) and $h s$-CRP is seen in COPD patients

Table 3 Distribution of hs-CRP and triglycerides of COPD and control subjects

\begin{tabular}{|l|l|l|l|}
\hline Parameters & & Control & COPD \\
\hline hs-CRP (mg/dL) & IQR & 2.75 & 3.50 \\
& Quartile I & 0.71 & 1.65 \\
& Median & 1.27 & 3.91 \\
& Quartile 3 & 3.46 & 5.15 \\
\hline \multirow{2}{*}{ Triglycerides (mg/dL) } & IQR & 125.25 & 37.75 \\
& Quartile I & 88.50 & 98.00 \\
& Median & 128.50 & 108.50 \\
& Quartile 3 & 213.75 & 135.75 \\
\hline
\end{tabular}

Abbreviation: $h s-C R P$, high sensitivity C-reactive protein; COPD, chronic obstructive pulmonary disease. $[(\mathrm{r}=0.4265, p=0.006) ;(\mathrm{r}=0.7034, p<0.001)$ and $(\mathrm{r}=0.7034$, $p<0.001)$, respectively]. Similar positive correlation was also seen in the control subjects $[(\mathrm{r}=0.4807, p=0.001) ;(\mathrm{r}=0.3557$, $p=0.024)$ and $(\mathrm{r}=0.3557, p=0.024)$, respectively $]$.

Bivariate correlations with C-reactive protein in low- and high-risk COPD subjects are presented in Table 5. Significant negative correlations between FVC and $h s$-CRP are seen in low-risk COPD subjects $(\mathrm{r}=-0.6014, p=0.042)$. Significant positive correlations between atherogenesis indices - cardiogenic risk ratio (CRR), atherogenic coefficient (AC) and $h s$ CRP are seen in low-risk COPD subjects $(\mathrm{r}=0.8462$, $p<0.001)$ for both the parameters. However, no correlation was observed in the high-risk COPD subjects.

The 10-year risk scores of the COPD subjects were calculated and presented in Table 6; FRS-CVD calculator could identify maximum number of subjects with high CVD risk (risk score $\geq 20 \%$ ) followed by JBS3 and QRISK 2 calculators. RRS calculator has stratified more than $50 \%$ of the subjects to have a 10 -year CVD risk to be less than $10 \%$.

The dichotomized risk score (high ie, $\geq 20 \%$ or low $<20 \%$ ) are presented in Table 7 . The pattern differed slightly on dichotomization of risk scores. RRS calculator again could identify only $10 \%$ of COPD subjects to be in high risk for CVD events. FRS-CVD calculator calculated that $45 \%$ of the subjects to be in high-risk category. JBS3 was second to FRS-CVD and QRISK2 performed intermediately by categorizing $35 \%$ and $30 \%$ of the COPD subjects to be in high-risk category, respectively.

\section{Discussion}

Comorbidities impact a large proportion of patients with COPD, with over $80 \%$ of patients with COPD estimated to have at least one comorbid chronic condition. ${ }^{27}$ In this study, out of 1283 COPD subjects visiting the hospital between study duration, 353 
Table 4 Bivariate correlations with C-reactive protein (hs-CRP) in COPD and control subjects

\begin{tabular}{|c|c|c|c|c|}
\hline \multirow[t]{2}{*}{ Parameters } & \multicolumn{2}{|l|}{ COPD } & \multicolumn{2}{|l|}{ Controls } \\
\hline & $\mathbf{r}$ & $p$-value & $\mathbf{r}$ & $p$-value \\
\hline Mean age, years & 0.1157 & 0.477 & -0.2646 & 0.099 \\
\hline Body Mass Index, $\mathrm{kg} / \mathrm{m}^{2}$ & 0.03913 & 0.810 & 0.2229 & 0.166 \\
\hline $\mathrm{FVC}(\mathrm{L})$ & 0.07339 & 0.652 & 0.1196 & 0.462 \\
\hline $\mathrm{FEV}_{1}, \%$ predicted & 0.2849 & 0.074 & -0.05389 & $0.74 I$ \\
\hline $\mathrm{FEV}_{\mathrm{I}} / \mathrm{FVC}, \%$ predicted & $0.0767 \mid$ & 0.638 & -0.0829 & 0.611 \\
\hline AIP & 0.4265 & $0.006^{* *}$ & 0.4807 & $0.00 I^{* *}$ \\
\hline CRR & 0.7034 & $<0.001 * * *$ & 0.3557 & $0.024^{*}$ \\
\hline $\mathrm{AC}$ & 0.7034 & $<0.001 * * *$ & 0.3557 & $0.024 *$ \\
\hline
\end{tabular}

Notes: Spearman's correlation test results; $*_{p}<0.05 ; * * p<0.01$; *** $p<0.001$.

Abbreviations: AIP, atherogenic index of plasma; CRR, cardiogenic risk ratio; AC, atherogenic coefficient; COPD, chronic obstructive pulmonary disease.

Table 5 Bivariate correlations with C-reactive protein (hs-CRP) in low- and high-risk COPD subjects

\begin{tabular}{|l|l|l|l|l|}
\hline \multirow{2}{*}{ Parameters } & \multicolumn{2}{|l|}{ Low risk } & \multicolumn{2}{l|}{ High risk } \\
\cline { 2 - 5 } & $\mathbf{r}$ & $\boldsymbol{p}$-value & $\mathbf{r}$ & \multicolumn{2}{l|}{-value } \\
\hline Mean age (years) & 0.0807 & 0.803 & 0.1062 & 0.590 \\
Body Mass Index $\left(\mathrm{kg} / \mathrm{m}^{2}\right)$ & 0.5079 & 0.094 & -0.0761 & 0.700 \\
FVC (L) & -0.6014 & $0.042^{*}$ & 0.05803 & 0.769 \\
FEV,$\%$ predicted & -0.1538 & 0.635 & 0.1202 & 0.542 \\
FEV /FVC, \% predicted & -0.09091 & 0.783 & -0.09678 & 0.624 \\
AIP & 0.5245 & 0.083 & 0.3354 & 0.081 \\
CRR & 0.8462 & $<0.00 I^{* * *}$ & 0.2724 & 0.160 \\
AC & 0.8462 & $<0.00 I^{* * *}$ & 0.2724 & 0.160 \\
\hline
\end{tabular}

Notes: Stages A and B are in the lower-risk group, and stages $C$ and D are in the higher-risk group. Spearman's correlation test results. ${ }^{*} p<0.05$; $* * * p<0.001$.

Abbreviations: AIP, atherogenic index of plasma; CRR, cardiogenic risk ratio; AC, atherogenic coefficient; FVC, forced vital capacity; FEVI, forced expiratory volume in one second; COPD, chronic obstructive pulmonary disease.

Table 6 10-year cardiovascular risk scores in COPD patients using different risk calculators

\begin{tabular}{|l|l|l|l|l|}
\hline 10-year risk & JBS3 & QRISK2 & RRS & FRS-CVD \\
\hline$<10 \%$ & $12(30)$ & $12(30)$ & $22(55)$ & $7(17.5)$ \\
$10 \%-<20 \%$ & $14(35)$ & $16(40)$ & $14(35)$ & $15(37.5)$ \\
$20 \%-<30 \%$ & $6(15)$ & $8(20)$ & $3(7.5)$ & $10(25)$ \\
$30 \%-<40 \%$ & $5(12.5)$ & $3(7.5)$ & $1(2.5)$ & $5(12.5)$ \\
$\geq 40 \%$ & $3(7.5)$ & $1(2.5)$ & $0(0.0)$ & $3(7.5)$ \\
\hline
\end{tabular}

Notes: Data presented as $n(\%)$.

Abbreviations: JBS3, Joint British Society risk calculator 3; QRISK2, Q-risk 2 by UK National Health Service; RRS, Reynolds risk score; FRS-CVD, Framingham risk scorecardiovascular disease (FRS-CVD); COPD, chronic obstructive pulmonary disease.

subjects $(27.5 \%)$ had two comorbidities and 566 subjects $(44 \%)$ had one comorbidity. The distribution of comorbid and concomitant conditions is shown in Figure 2. We also found a similar prevalence of comorbidities in COPD subjects as reported in the previous publication where comorbidities like CVDs contribute to $29-70 \%$ and diabetes $10-23 \%$. $^{27}$
IHD (20-60\%), heart failure (10-30\%) and cardiac arrhythmias (10-15\%) are among the most commonly observed CVDs reported in people with COPD. ${ }^{28}$ During the study period, we found 18 cases of ischemic heart disease and 15 cases of heart failure leading to hospitalization.

We found a higher serum C-reactive protein level in subjects with COPD than in control subjects. The serum level of low-density lipoprotein cholesterol, atherogenic indices like cardiogenic risk ratio and atherogenic coefficient were significantly higher and serum high-density lipoprotein levels were significantly lower in subjects with COPD than in control subjects. These findings were in line with the results of the previous studies. ${ }^{6-8,29}$

The results from the present study also show that atherogenic lipid profiles and atherogenic indices (cardiogenic risk ratio and atherogenic coefficient) were increased significantly in subjects with COPD than in control subjects. Using bivariate correlations, significant positive 
Table 7 10-year dichotomized cardiovascular risk categories in COPD patients

\begin{tabular}{|l|l|l|l|l|}
\hline 10-year risk & JBS3 & QRISK2 & RRS & FRS-CVD \\
\hline$<20 \%$ & $26(65)$ & $28(70)$ & $36(90)$ & $22(55)$ \\
$\geq 20 \%$ & $14(35)$ & $12(30)$ & $4(10)$ & $18(45)$ \\
\hline
\end{tabular}

Notes: Data presented as $\mathrm{n}(\%)$.

Abbreviations: JBS3, Joint British Society risk calculator 3; QRISK2, Q-risk 2 by UK National Health Service; RRS, Reynolds risk score; FRS-CVD, Framingham risk score-cardiovascular disease (FRS-CVD); COPD, chronic obstructive pulmonary disease.

correlations between atherogenic indices, AIP, CRR and AC were found with $h s$-CRP in both COPD and control subjects. We additionally found that the correlation of $h s-$ CRP with atherogenic indices was significantly positive for cardiogenic risk ratio and atherogenic coefficient in low-risk COPD subjects only. No correlation was seen in the high-risk COPD subjects. A significant negative correlation was also seen with FVC and $h s$-CRP in low-risk COPD cases.

COPD is a known major leading cause of morbidity and mortality worldwide and exists frequently with other diseases impacting the prognosis. CVDs including heart failure, systemic hypertension, atrial fibrillation and ischemic and atherosclerotic heart disease are a known major comorbidity in patients with COPD. ${ }^{1}$ The patients with COPD might have a higher risk for CVD, and patients with CVD might have a higher risk for COPD. The association between airway obstruction in COPD and CVD found in our study is in line with the other studies. ${ }^{3-5,30}$

Traditionally, dyslipidemia is considered to be one of the most important risk factors for the development of atherogenesis and to assess the CV risk. Increased LDL cholesterol levels and decreased HDL cholesterol levels are indicative of an atherogenic lipid pattern. ${ }^{31}$ C-reactive protein is an inflammatory marker and indicator of disease activity in COPD and is also related to higher CVD risk and atherogenesis. ${ }^{3,32}$ Chronic systemic inflammatory response with increased levels of C-reactive protein has been investigated in some studies explaining the development of concomitant chronic diseases in the same subject. ${ }^{43-35}$ The prevalence of ischemic heart diseases (including myocardial infarction, coronary stenosis and angina pectoris) in subjects with COPD was reported to be between $4.7 \%$ and $60 \%{ }^{3}$ Lipid ratios called the atherogenic indices were assessed to identify patients with chronic diseases (COPD included) at high risk of developing CVD. ${ }^{6-9}$ Previous studies have established that LDL-C concentration might be a moderator of the contribution of $h s-C R P$ to vascular events. ${ }^{36-38}$
Systemic inflammation has a role in endothelial dysfunction and is associated with the risk of CVDs and mortality. ${ }^{39}$ Inflammation participates critically in atherosclerosis. Circulating levels of several inflammatory markers rise in individuals at risk for atherosclerotic events. In particular, elevation of plasma CRP, a nonspecific acutephase reactant that is easily and reliably measured, has strong predictive power for $\mathrm{CV}$ events such as incident myocardial infarction, stroke, peripheral arterial disease and sudden cardiac death. ${ }^{40}$ In our study, hs-CRP levels were significantly increased in COPD cases than in control subjects. Several studies have demonstrated that the concentration of CRP is increased in COPD patients as compared to control subjects. $5,13,15,16,41,42$ However, CRP is an acute phase protein and is elevated during many conditions. Considering the same, other inflammatory conditions such as COPD cases with exacerbation, patients with recent or ongoing infections, patients with tuberculosis, liver disease, rheumatoid arthritis or systemic lupus erythematosus were excluded. Smoking status and the habit duration in pack-years were found to be significantly more in the COPD subjects than the control subjects. Smoking in pack-years is a significant predictor of CRP levels. ${ }^{43}$ Several studies have shown that current smokers have higher CRP levels than non-smokers and that there is a positive association with the number of pack-years smoked. $^{44,45}$

CRP and FVC (\% of predicted) values were negatively correlated in our study, and FVC (\% of predicted) was associated with abnormal CRP levels in a multivariate analysis. The negative associations between CRP and FVC have been previously demonstrated in several studies. ${ }^{39,46,47}$

For the prevention of CVDs, it is essential to find out 10 -year CV risk that can help in identifying high CVD risk individuals, albeit without underestimating or overestimating the risk. In the present study, the FRS-CVD risk calculator was found to perform the best followed by JBS3 and QRISK2. FRS-CVD calculator was able to categorize maximum number of subjects into high-risk category for CV events. QRISK2, JBS3 have performed intermediately. RRS calculator performed poorly by identifying least number of COPD subjects to be in high-risk category. Overall, RRS calculator underestimated the CV risk as compared to JBS3, QRISK2 and FRS-CVD. The present study also supports the findings of other studies in the Indian population where FRS-CVD and JBS3 calculators have performed the best. ${ }^{4-50}$ 


\section{Limitation}

This study relies on history of CVD recorded as a part of medical history. No further examination was done to assess any CVD risk. Although the $\mathrm{CV}$ risk in COPD patients was assessed using various $\mathrm{CV}$ risk score calculators, the comparison of various CV risk score was not the primary objective of the study. The present study provided an indicator that can be confirmed in further studies comprising heterogeneous Indian population.

\section{Conclusion}

The study concluded that $h s$-CRP levels in COPD subjects were significantly higher than in control subjects. There was a positive correlation between atherogenic indices including atherogenic index of plasma, cardiogenic risk ratio and atherogenic coefficient with $h s$-CRP, suggesting that atherogenic indices can be used as early predictors of CV risk in subjects with COPD. FRS-CVD calculator was most useful for identifying high $\mathrm{CV}$ risk subjects in COPD subjects. Hence, we believe that $h s$-CRP and FRS-CVD can be used for assessing the $\mathrm{CV}$ risk and the atherogenic indices can be used as a preliminary indication of accelerated atherosclerosis in COPD subjects. These results, if confirmed in large prospective follow-up studies using cases as "COPD patients with atherosclerosis" and control as "COPD patients without atherosclerosis", can effectively comment on the impact of COPD on CV risk of the patients.

\section{Acknowledgments}

We express special thanks to Mr. Arjun Roy, Chief Operating Offer, Karmic Lifesciences LLP, Ahmedabad, India, for help in sample size calculation and statistical analysis for this study. The authors thank all the personnel of Hamdard Institute of Medical Sciences \& Research, Jamia Hamdard, New Delhi, India, for their essential and altruistic collaboration which enabled the conduct of this study.

\section{Disclosure}

The authors report no conflicts of interest in this work.

\section{References}

1. Global Initiative for Chronic Obstructive Lung Disease. Global Strategy for the Diagnosis, Management, and Prevention of Chronic Obstructive Pulmonary Disease. [Updated 2016]. Available from: https://goldcoped.org/. Accessed April 30, 2016.

2. WHO Fact sheet: the top 10 causes of death dated 24 May 2018. Available from: https://www.who.int/news-room/fact-sheets/detail/thetop-10-causes-of-death. Accessed May 14, 2019
3. Roversi S, Roversi P, Spadafora G, Rossi R, Fabbri LM. Coronary artery disease concomitant with chronic obstructive pulmonary disease. Eur J Clin Invest. 2014;44(1):93-102. doi:10.1111/eci.12181

4. Corbi G, Bianco A, Turchiarelli V, et al. Potential mechanisms linking atherosclerosis and increased cardiovascular risk in COPD: focus on Sirtuins. Int J Mol Sci. 2013;14(6):12696-12713. doi:10.3390/ ijms 140612696

5. Bellocchia M, Masoero M, Ciuffreda A, et al. Predictors of cardiovascular disease in asthma and chronic obstructive pulmonary disease. Multidiscip Respir Med. 2013;8(1):58. doi:10.1186/2049-6958-8-58

6. Acay A, Ulu MS, Ahsen A, et al. Atherogenic index as a predictor of atherosclerosis in subjects with familial Mediterranean fever. Medicina. 2014;50(6):329-333. doi:10.1016/j.medici.2014.11.009

7. Singh M, Pathak MS, Paul A. A study on atherogenic indices of pregnancy induced hypertension patients as compared to normal pregnant women. J Clin Diagn Res. 2015;9(7):Bc05-Bc08. doi:10.7860/JCDR/2015/13505.6241

8. Millan J, Pinto X, Munoz A, et al. Lipoprotein ratios: physiological significance and clinical usefulness in cardiovascular prevention. Vasc Health Risk Manag. 2009;5:757-765.

9. Essiarab F, Taki H, Lebrazi H, Sabri M, Saile R. Usefulness of lipid ratios and atherogenic index of plasma in obese Moroccan women with or without metabolic syndrome. Ethn Dis. 2014;24(2):207-212.

10. D'Agostino RB Sr, Vasan RS, Pencina MJ, et al. General cardiovascular risk profile for use in primary care: the Framingham Heart Study. Circulation. 2008;117(6):743-753. doi:10.1161/ CIRCULATIONAHA.107.699579

11. Hippisley-Cox J, Coupland C, Vinogradova Y, et al. Predicting cardiovascular risk in England and Wales: prospective derivation and validation of QRISK2. BMJ. 2008;336(7659):1475-1482. doi:10.1136/bmj.39609.449676.25

12. Assmann G, Cullen P, Schulte H. Simple scoring scheme for calculating the risk of acute coronary events based on the 10-year followup of the prospective cardiovascular Munster (PROCAM) study. Circulation. 2002;105(3):310-315. doi:10.1161/hc0302.102575

13. Schols AM, Buurman WA, Staal van Den Brekel AJ, Dentener MA, Wouters EF. Evidence for a relation between metabolic derangements and increased levels of inflammatory mediators in a subgroup of patients with chronic obstructive pulmonary disease. Thorax. 1996;51(8):819-824. doi:10.1136/thx.51.8.819

14. Broekhuizen R, Wouters EF, Creutzberg EC, Schols AM. Raised CRP levels mark metabolic and functional impairment in advanced COPD. Thorax. 2006;61(1):17-22. doi:10.1136/thx.2005.041996

15. de Torres JP, Cordoba-Lanus E, Lopez-Aguilar C, et al. C-reactive protein levels and clinically important predictive outcomes in stable COPD patients. Eur Respir J. 2006;27(5):902-907. doi:10.1183/ 09031936.06.00109605

16. Karadag F, Kirdar S, Karul AB, Ceylan E. The value of C-reactive protein as a marker of systemic inflammation in stable chronic obstructive pulmonary disease. Eur J Intern Med. 2008;19(2):104108. doi:10.1016/j.ejim.2007.04.026

17. von Elm E, Altman DG, Egger M, Pocock SJ, Gøtzsche PC, Vandenbroucke JP; STROBE Initiative. The Strengthening the Reporting of Observational Studies in Epidemiology (STROBE) statement: guidelines for reporting observational studies. Int J Surg. 2014;12 (12):1495-1499. Epub 2014 July 18. doi:10.1016/j.ijsu.2014.07.013

18. World Medical Association. World Medical Association Declaration of Helsinki: ethical principles for medical research involving human subjects. JAMA. 2013;310(20):2191-2194. doi:10.1001/jama.2013.281053

19. International Ethical Guidelines for Epidemiological Studies. Prepared by the Council for International Organizations of Medical Sciences (CIOMS) in Collaboration with the World Health Organization (WHO); 2009. Available from: https://cioms.ch/wp-content/uploads/ 2017/01/International_Ethical_Guidelines_LR.pdf. Accessed May 13, 2019. 
20. Meenakshisundaram R, Rajendiran C, Thirumalaikolundusubramanian P. Lipid and lipoprotein profiles among middle aged male smokers: a study from southern India. Tob Induc Dis. 2010;8:11. doi:10.1186/16179625-8-11

21. Miller MR, Crapo R, Hankinson J, et al. General considerations for lung function testing. Eur Respir J. 2005;26(1):153-161. doi:10.1183/09031936.05.00034505

22. Miller MR, Hankinson J, Brusasco V, et al. Standardisation of spirometry. Eur Respir J. 2005;26(2):319-338. doi:10.1183/09031936.05.00034805

23. Pellegrino R, Viegi G, Brusasco V, et al. Interpretative strategies for lung function tests. Eur Respir J. 2005;26(5):948-968. doi:10.1183/ 09031936.05.00035205

24. Çakırca G, Çelik MM. Lipid profile and atherogenic indices and their association with platelet indices in familial Mediterranean fever. Turk Kardiyol Dern Ars. 2018;46(3):184-190. doi:10.5543/ tkda.2018.93762

25. Tillin T, Hughes AD, Whincup P, et al. Ethnicity and prediction of cardiovascular disease: performance of QRISK2 and Framingham scores in a U.K. tri-ethnic prospective cohort study (SABRESouthall And Brent REvisited). Heart. 2014;100(1):60-67. doi:10.1136/heartjnl-2013-304474

26. Collins GS, Altman DG. An independent and external validation of QRISK2 cardiovascular disease risk score: a prospective open cohort study. BMJ. 2010;340:c2442. doi:10.1136/bmj.c293

27. Putcha N, Drummond MB, Wise RA, Hansel NN. Comorbidities and chronic obstructive pulmonary disease: prevalence, influence on outcomes, and management. Semin Respir Crit Care Med. 2015;36 (4):575-591. doi:10.1055/s-0035-1556063

28. Morgan AD, Zakeri R, Quint JK. Defining the relationship between COPD and CVD: what are the implications for clinical practice? Ther Adv Respir Dis. 2018;12:1-16. doi:10.1177/1753465817750524

29. Tautu OF, Darabont R, Onciul S, et al. New cardiovascular risk factors and their use for an accurate cardiovascular risk assessment in hypertensive patients. Maedica. 2014;9(2):127-134.

30. Schnell K, Weiss CO, Lee T, et al. The prevalence of clinicallyrelevant comorbid conditions in patients with physician-diagnosed COPD: a cross-sectional study using data from NHANES 19992008. BMC Pulm Med. 2012;12:26. doi:10.1186/1471-2466-12-26

31. Burtis CA, Ashwood ER, Bruns DE, editors. Tietz Textbook of Clinical Chemistry and Molecular Diagnosis (5th edition). St. Louis, USA: Elsevier ; 2012:2238. ISBN: 978-1-4160-6164-9.

32. Hancox RJ, Poulton R, Greene JM, et al. Systemic inflammation and lung function in young adults. Thorax. 2007;62(12):1064-1068. doi: $10.1136 /$ thx.2006.076877

33. Iwamoto H, Yokoyama A, Kitahara Y, et al. Airflow limitation in smokers is associated with subclinical atherosclerosis. Am J Respir Crit Care Med. 2009;179(1):35-40. doi:10.1164/rccm.200804-560OC

34. Sin DD, Man SF. Why are patients with chronic obstructive pulmonary disease at increased risk of cardiovascular diseases? The potential role of systemic inflammation in chronic obstructive pulmonary disease. Circulation. 2003;107(11):1514-1519. doi:10.1161/ 01.cir.0000056767.69054.b3

35. Maclay JD, McAllister DA, Macnee W. Cardiovascular risk in chronic obstructive pulmonary disease. Respirology. 2007;12 (5):634-641. doi:10.1111/j.1440-1843.2007.01136.x

36. Lin GM, Liu K, Colangelo LA, Lakoski SG, Tracy RP, Greenland P. Low-density lipoprotein cholesterol concentrations and association of high-sensitivity C-reactive protein concentrations with incident coronary heart disease in the multi-ethnic study of atherosclerosis. $\mathrm{Am} \mathrm{J}$ Epidemiol. 2016;183(1):46-52. doi:10.1093/aje/kwv144
37. Ridker PM, Rifai N, Clearfield M, et al. Measurement of C-reactive protein for the targeting of statin therapy in the primary prevention of acute coronary events. $N$ Engl J Med. 2001;344(26):1959-1965. doi:10.1056/NEJM200106283442601

38. Ridker PM, Rifai N, Rose L, Buring JE, Cook NR. Comparison of Creactive protein and low-density lipoprotein cholesterol levels in the prediction of first cardiovascular events. $N$ Engl J Med. 2002;347 (20):1557-1565. doi:10.1056/NEJMoa021993

39. Emerging Risk Factors Collaboration, Kaptoge S, Di Angelantonio E, et al. C-reactive protein concentration and risk of coronary heart disease, stroke, and mortality: an individual participant meta-analysis. Lancet. 2010;375(9709):132-140. doi:10.1016/S0140-6736(09) 61717-7

40. Riker PM. Clinical application of C-reactive protein for cardiovascular disease detection and prevention. Circulation. 2003;107:363369. doi:10.1161/01.cir.0000053730.47739.3c

41. Gan WQ, Man SF, Senthilselvan A, Sin DD. Association between chronic obstructive pulmonary disease and systemic inflammation: a systematic review and a meta-analysis. Thorax. 2004;59(7):574-580. doi: $10.1136 /$ thx.2003.019588

42. Zhang Y, Bunjhoo H, Xiong W, Xu Y, Yang D. Association between Creactive protein concentration and chronic obstructive pulmonary disease: a systematic review and meta-analysis. J Int Med Res. 2012;40 (5):1629-1635. doi:10.1177/030006051204000501

43. El-Deek SE, Makhlouf HA, Saleem TH, Mandour MA, Mohamed NA. Surfactant protein D, soluble intercellular adhesion molecule-1 and high-sensitivity C-reactive protein as biomarkers of chronic obstructive pulmonary disease. Med Prin Pract. 2013;22(5):469474. doi:10.1159/000349934

44. Frohlich M, Sund M, Lowel H, Imhof A, Hoffmeister A, Koenig W. Independent association of various smoking characteristics with markers of systemic inflammation in men. Results from a representative sample of the general population (MONICA Augsburg Survey 1994/95). Eur Heart J. 2003;24(14):1365-1372. doi:10.1016/s0195-668x(03)00260-4

45. Danesh J, Wheeler JG, Hirschfield GM, et al. C-reactive protein and other circulating markers of inflammation in the prediction of coronary heart disease. $N$ Engl J Med. 2004;350(14):1387-1397. doi:10.1056/NEJMoa032804

46. van Durme YM, Verhamme KM, Aarnoudse AJ, et al. C-reactive protein levels, haplotypes, and the risk of incident chronic obstructive pulmonary disease. Am J Respir Crit Care Med. 2009;179(5):375382. doi:10.1164/rccm.200810-1540OC

47. Dahl M, Vestbo J, Zacho J, Lange P, Tybjaerg-Hansen A, Nordestgaard BG. C reactive protein and chronic obstructive pulmonary disease: a Mendelian randomisation approach. Thorax. 2011;66(3):197-204. doi:10.1136/thx.2009.131193

48. Garg N, Muduli SK, Kapoor A, et al. Comparison of different cardiovascular risk score calculators for cardiovascular risk prediction and guideline recommended statin uses. Indian Heart J. 2017;69 (4):458-463. doi:10.1016/j.ihj.2017.01.015

49. Bansal M, Kasliwal RR, Trehan N. Comparative accuracy of different risk scores in assessing cardiovascular risk in Indians: a study in patients with first myocardial infarction. Indian Heart J. 2014;66 (6):580-586. doi:10.1016/j.ihj.2014.10.399

50. Bansal M, Kasliwal RR, Trehan N. Relationship between different cardiovascular risk scores and measures of subclinical atherosclerosis in an Indian population. Indian Heart J. 2015;67(4):332-340. doi:10.1016/j.ihj.2015.04.017 


\section{Publish your work in this journal}

Therapeutics and Clinical Risk Management is an international, peerreviewed journal of clinical therapeutics and risk management, focusing on concise rapid reporting of clinical studies in all therapeutic areas outcomes, safety, and programs for the effective, safe, and sustained use of medicines. This journal is indexed on PubMed Central, CAS,
EMBase, Scopus and the Elsevier Bibliographic databases. The manuscript management system is completely online and includes a very quick and fair peer-review system, which is all easy to use. Visit http://www.dovepress.com/testimonials.php to read real quotes from published authors.

Submit your manuscript here: https://www.dovepress.com/therapeutics-and-clinical-risk-management-journal 